\title{
Efficacy of an Aromatic Vinegar in Reducing Psychrotrophic Bacteria and Biogenic Amines in Salmon Fillets (Salmo salar) Stored in Modified Atmosphere Packaging
}

\author{
Jessica Di Toro ${ }^{1}$, Raffaella Branciari ${ }^{1, *}$, Rossana Roila ${ }^{1}$, Serena Altissimi ${ }^{2}$, Haiyang Jang ${ }^{3}$, \\ Kang Zhou ${ }^{3}$, Simona Perucci ${ }^{4}$, Michaela Codini ${ }^{5}$, David Ranucci ${ }^{1}$
}

\author{
'Department of Veterinary Medicine, University of Perugia, Via San Costanzo 4, 06123 Perugia, Italy \\ ${ }^{2}$ Istituto Zooprofilattico Sperimentale dell'Umbria e delle Marche "Togo Rosati", Via G. Salvemini, 1, 06126, Perugia, Italy \\ ${ }^{3}$ College of Food Science, Sichuan Agricultural University, 46 Xinkang Rd, Ya'an, Sichuan, China \\ ${ }^{4}$ Freelance researcher, Perugia, Italy \\ ${ }^{5}$ Department of Pharmaceutical Science, University of Perugia, Via San Costanzo 4, 06123 Perugia, Italy
}

Key words: salmon, vinegar, spoilage bacteria, MAP, biogenic amines

Salmon flesh spoilage can be greatly reduced through the use of preservation methods, using natural products combined with low temperature and packaging. Microbiological and physicochemical characteristics of fresh salmon fillets (Salmo salar), sprayed with an aromatic vinegar and stored in modified atmosphere packaging, were investigated. Fillets were kept at $4^{\circ} \mathrm{C}$ and sampled after $2 \mathrm{~h}$ and 3,7 and 10 days. An untreated control group was used as well. Fish samples were analysed for microbiological (total viable count, Enterobacteriaceae, psychrotrophic microbial count, Pseudomonas spp.) and physicochemical (pH, colour, total volatile basic nitrogen, and biogenic amines) properties. Aromatic vinegar was found to beneficially contribute to the hygienic quality of the salmon, reducing microbial growth during storage and exerting a positive effect, mainly on psychrotrophic loads and Pseudomonas spp. The treatment had a positive effect on biogenic amine levels, showing lower values for histamine, putrescine, cadaverine, and tyramine.

\section{INTRODUCTION}

In the Western world, people are paying more attention to healthy eating; as a result of which seafood, including fish, crustaceans, molluscs and edible aquatic plants, is in high demand as an important source of omega 3 fatty acids [Branciari et al., 2017; Leisner \& Gram, 2014; Tacon \& Metian, 2013]. Aquaculture is the fastest growing food sector worldwide, and among seafood, farmed salmon is one of the most highly valued products [Briones et al., 2010; FAO, 2016], from both the nutritional and the economic perspectives [Sivertsvik et al., 2003]. Aquaculturists face many challenges to meet the global food demand while maintaining a high-quality product. Due to its high nutritional quality, fresh salmon is popular and is consumed throughout the world; however, it is also prone to spoilage [Wang et al., 2017a]. Food structure, together with chemical composition and storage conditions (temperature, time, packaging system, light, and antimicrobials), strongly affect the growth and proliferation of microorganisms [Corbo et al., 2009]. Indeed, fish is one of the most perishable food products [Fidalgo et al., 2018] due to the presence of non-protein nitrogenous substances, lipid composition, neutral $\mathrm{pH}$ and a high moisture content

\footnotetext{
* Corresponding Author: E-mail: raffaella.branciari@unipg.it (R. Branciari)

which are suitable conditions for microbial proliferation [Miraglia et al., 2016]. Microbial growth and activity are primarily responsible for the development of off-odours and off-flavours that make non-frozen fish products unacceptable or spoiled [Leisner \& Gram, 2014] and can pose a significant threat to the health of consumers [Ozogul et al., 2017].

Market needs, added to consumer demand for fresh, refrigerated, minimally-processed and long-life food, have led to a considerable research effort aimed to define new technologies able to preserve texture, flavour and nutritional value and to ensure fresh fishery products' safety and quality [Fernández et al., 2009; Miks-Krajnik et al., 2016; Sallam, 2007]. Various methods of preservation have been assessed, investigating their effects on water activity, $\mathrm{pH}$, low temperature or modified atmosphere packaging. These parameters have been shown to have a great effect on the microbial flora of fish and on the corresponding spoilage pattern [Leisner \& Gram, 2014]. Green consumerism, that is the growing demand for fewer chemical preservatives, environmentally friendly antimicrobials and the sustainable use of molecules of natural origin [Corbo et al., 2009], together with the demand for high-quality fresh seafood, has intensified the search for technologies that favour fresh fish utilisation. Nevertheless, effects of modified atmosphere packaging (MAP) of fresh fish are controversial with author who report 
limited extension [Emborg et al., 2002] or an improvement of fish shelf life but in relation to fish species, initial microbial load, gas mixture, and temperature of storage [Emborg et al., 2002]. Among natural products, vinegar shows a significant biological activity, including sanitising characteristics and antioxidant effects [Lingham et al., 2012; Machado et al., 2011]. It is recognised as a natural antimicrobial and antioxidant product that may improve safety and enhance shelf life, provide acceptable sensory quality and reduce economic losses due to spoilage of fish products [Lingham et al., 2012].

In view of what has been said regarding the importance of fish from a nutritional, qualitative, and economic standpoint, the purpose of this study was to investigate the effects of surface treatment with an aromatic vinegar on some microbiological and physicochemical parameters related to the quality and safety of salmon fillets stored in MAP, and thus to reduce the bacterial populations, to determine changes in biogenic amines of the fish, which are beneficial for producer interest and consumer safety.

\section{MATERIALS AND METHODS}

\section{Experimental design}

Chilled fillets of salmon (Salmo salar) and aromatic vinegar (AV) obtained from sugar cane (Aromatic Vinegar GPI 6.2 ${ }^{\circledR}$ - Lazzari Equipment \& Packaging, Settimo di Pescantina, VR, Italy) were purchased from a local factory (Circeo Pesca S.r.l., San Mariano-Corciano, PG, Italy). Fillets were obtained seven days after harvesting from salmon weighing between 3 and $4 \mathrm{~kg}$, stored in ice till filleting. The fillets were then divided in $150 \mathrm{~g}$ portions (12 g standard deviation) presenting both side (inner and outer part) and ventral and dorsal parts (surface of $90 \mathrm{~cm}^{2}$ approximately). The skin was left on the outer side according to producer needs.

In order to perform analytical determinations of $\mathrm{AV}$, on the first day of the trial, $100 \mathrm{~mL}$ of the product were sampled in triplicate from each of three vats containing $23 \mathrm{~L}$ of AV. Salmon fillets (150 g each) were treated by spraying homogeneously their inner surface with $1.5 \mathrm{~mL} \mathrm{AV/150 \textrm {g }}$ of product by a hand nebulizer and subsequently packaged on polystyrene trays (Sirap-Gema S.p.A., Verolanuova, Italy) under MAP (Delta 2000; Ilapak Italia S.p.A. Foiano della Chiana, Italy) and covered with a stretch-film (Cryovac® BDFS100; thickness $=21 \mu \mathrm{m}$; density $=0.943 \mathrm{~g} / \mathrm{cm}^{3}$; Permeability: $\mathrm{CO}^{2}=100 \mathrm{~cm}^{3} / \mathrm{m}^{2}, 24 \mathrm{~h} ; \mathrm{O}^{2}=25 \mathrm{~cm}^{3} / \mathrm{m}^{2}, 24 \mathrm{~h}$ ); they were referred to as the AV group. Untreated salmon fillets, stored at the same conditions as AV samples, were employed as a control group (C group). The gas content of MAP was measured using a CheckPoint Handheld Gas Analyser (PBI Dansensor, Ringsted, Denmark), and $\mathrm{O}_{2}$ and $\mathrm{CO}_{2}$ ranged from $13.46 \%$ and $28.22 \%$ on day 0 to $13.92 \%$ and $16.52 \%$ on day 10 of storage, respectively.

All fish samples were kept in the dark during storage under refrigeration $\left(4 \pm 1^{\circ} \mathrm{C}\right)$ directly at factory level and were collected after 2 h (T1), 3 days (T3), 7 days (T7) (shelf life of the salmon fillets defined by the producer), and 10 days (T10). At each sampling point, a total of 20 samples were used, 10 each for both $\mathrm{AV}$ and $\mathrm{C}$ groups. All the fillets and $\mathrm{AV}$ samples were transported in refrigerated conditions $\left(4 \pm 1^{\circ} \mathrm{C}\right)$ to the laboratory at the Department of Veterinary Medicine (University of Perugia, Italy) and promptly processed for microbiological and physicochemical analysis.

\section{Physical-chemical determination of the aromatic vinegar}

Vinegar samples were analysed for $\mathrm{pH}$ value, using a $\mathrm{pH}$ meter equipped with an insertion electrode (Crison $\mathrm{pH} 25$, Crison, Barcelona, Spain). Total polyphenols content (TPC) was determined using the Folin-Ciocalteu colorimetric method [Rashidinejad et al., 2013] using an Ultrospec 2100 pro UV/visible spectrometer (Amersham Pharmacia Biotech, Buckinghamshire, UK) at $765 \mathrm{~nm}$. The phenolic content was calculated based on a gallic acid calibration curve as reported in Miraglia et al. [2017] ( $\left.\mathrm{y}=0.001 \mathrm{x}-0.0273, \mathrm{R}^{2}=0.9943\right)$. The content was expressed as $\mathrm{mg}$ gallic acid equivalents (GAE) per mL. No microbiological analyses were performed for vinegar, considering the characteristic of the products, and the product sheet reports (Lazzari Equipment \& Packaging, Settimo di Pescantina, VR, Italy): total bacterial count $<5000$ colony-forming units $(\mathrm{CFU}) / \mathrm{g}$; yeasts and moulds < 300 CFU/g; Salmonella spp., Listeria monocytogenes, Escherichia coli, and Staphylococcus aureus absent in $25 \mathrm{~g}$.

\section{Microbiological analysis of salmon fillets}

For sample preparation, a portion of $10 \mathrm{~g}( \pm 0.1 \mathrm{~g})$ from the upper left side of each salmon fillet was sampled using aseptic blades and forceps and was transferred into a sterile stomacher bag with $90 \mathrm{~mL}$ of sterile peptone water. After homogenisation (Stomacher 400 circulator; Seward Ltd, Norfolk, UK), the following microbial counts were determined: total viable count (TVC) according to ISO 4833-1:2013; Enterobacteriaceae count according to ISO 21528-2:2017; psychrotrophic microbial count according to ISO 17410:2001; and Pseudomonas spp. count by the spread method: $0.1 \mathrm{~mL}$ was incubated in Pseudomonas CFC Selective Agar Base (Biolife, Milan, Italy) plates, that were incubated at $25^{\circ} \mathrm{C}$ for $24 \mathrm{~h}$ in aerobic conditions. Results of microbial analyses are expressed as $\log \mathrm{CFU} / \mathrm{g}$.

Salmonella spp. detection was performed according to ISO 6579-1:2017, and L. monocytogenes presence was investigated according to ISO 11290-1:2017.

\section{Physical-chemical determinations of salmon fillets}

Colour was evaluated on the cut surface of the fillet with a colorimeter (Minolta CR 400, Osaka, Japan) using the CIE $\mathrm{L}^{*} \mathrm{a}^{*} \mathrm{~b}^{*}$ system [CIE, 1986], and the measurements were performed in duplicate on the dorsal and ventral part of each fillet. Results are expressed as mean values of four measurements. The $\mathrm{pH}$ value of each salmon fillet was determined in the right dorsal part of the fillets in triplicate using a $\mathrm{pH}$ meter equipped with an insertion probe (Crison 25, Crison, Barcelona, Spain). Water activity $\left(a_{w}\right)$ was determined using a HygroLab 3 hygrometer (Rotronic, Huntington, NY, USA) on three samples collected from the upper right part of the fillets. Total volatile basic nitrogen (TVB-N) content was determined in duplicate at the lower right part of the fillets according to Pearson [1991].

Content of biogenic amines (BA) was determined in eight samples for each treatment at each sampling point considered. BA extraction from the samples was carried out according to 
the procedures developed by Zhai et al. [2012] with a little modification. Five grams of each sample was transferred into a centrifuge tube containing $5 \%(\mathrm{w} / \mathrm{v})$ trichloroacetic acid (TCA). The mixture was vortexed and centrifuged at $10,000 \times g$ for $5 \mathrm{~min}$ at $4^{\circ} \mathrm{C}$. The supernatant was collected, and the residue was extracted again with the same volume of TCA. Both supernatants were filtered through Whatman paper No. 1 and combined. The final volume was adjusted to $25 \mathrm{~mL}$ with TCA. BA derivatization and quantification was carried out according to the procedures described by Zhai et al. [2012]; the quantification was performed using high--performance liquid chromatography (HPLC) analysis using a Shimadzu RF-20AXS instrument (Kyoto, Japan) consisting of a vacuum degasser, a quaternary pump, an autosampler, a thermostatted column compartment, and a fluorescent detector. Histamine (HIS, 98\%), tryptamine (TRP, 98\%), cadaverine (CAD, 98\%) and 2-phenylethylamine (2-PHE, 99.5\%) were purchased as standards from Sigma Aldrich Italia (Milan, Italy); whereas spermine (SPM, 97\%), tyramine (TYR, 99\%), putrescine (PUT, 98\%), and spermidine (SPD, 98\%) were purchased as hydrochloride salts (Sigma Aldrich). Results were expressed as $\mathrm{mg} / \mathrm{kg}$.

\section{Statistical analysis}

The data of the different parameters considered were analysed by an ANOVA model (SAS Institute Inc., Cary, NC, USA) with treatment (AV, C) and time (T1, T3, T7, and T10) as fixed and variable factors, respectively, and their interactions. The ComBase software tool DMfit (Baranyi and Roberts model) was used to determine growth curves for all the microbial populations considered in $\mathrm{AV}$ and $\mathrm{C}$ samples. The results of the model, expressed as initial value, shoulder, $\mu$ max and final value, were analysed by a one-way ANOVA model (SAS Institute Inc., Cary, NC, USA). For all these parameters, the difference between the means was analysed with the Tukey test and considered significant at a $\mathrm{p}$ value $<0.05$.

\section{RESULTS AND DISCUSSION}

\section{pH and TPC of aromatic vinegar}

In order to assess the peculiar characteristics of the treatment, $\mathrm{pH}$ and TPC analyses were performed in the AV. The average $\mathrm{pH}$ value recorded was 6.20 (0.08 standard de- viation), and the TPC value was $2.6 \mathrm{mg} \mathrm{GAE} / \mathrm{mL}$ (0.2 standard deviation). The $\mathrm{pH}$ was exactly comparable to that reported in the product sheet, and relatively high compared to other vinegars reported in the literature as antimicrobials [Medina et al., 2007]. The TPC was comparable to that reported in other vinegars [Machado et al., 2011] but lower than those found in other natural compounds adopted in fish fillets and reported in the literature [Choulitoudi et al., 2016].

\section{Salmon fillet microbiology}

The microbial loads of fish fillets are shown in Figure 1. In order to assess whether the use of AV had any effect on bacterial growth in salmon fillets, microbiological data were analysed using ComBase, and the microbial responses are reported in Table 1. The parameters considered were initial value (log CFU/g), lag/shoulder (h), $\mu$ max (Log CFU/g/h), and final value (log CFU/g) [Baranyi \& Tamplin, 2004].

Counts of all bacterial groups increased throughout the storage experiment at chilled temperature, showing initial counts between $10^{2}$ and $10^{4} \mathrm{CFU} / \mathrm{g}$ (Table 1). Salmon fillets were considered to be in good condition for human consumption before the storage experiment, as the initial contamination level for raw fish at time zero should be below $10^{6} \mathrm{CFU} / \mathrm{g}$ of TVC as reported by Miks-Krajnik et al. [2016]. Initial TVC was between 4.35 and $4.59 \mathrm{Log} \mathrm{CFU} / \mathrm{g}$ for the two groups, which was slightly lower than reported by Fidalgo et al. [2018] but in accordance with values reported by Chytiri et al. [2004]. The final TVC values were lower than those reported in the literature that reached $8 \log \mathrm{CFU} / \mathrm{g}$ after 6 days of storage [Fidalgo et al., 2018; Miraglia et al., 2016]. No differences in the final TVC were recorded; therefore, it was shown that the treatment had no effect on TVC.

Initial Enterobacteriaceae loads varied between 2.37 and $2.50 \log \mathrm{CFU} / \mathrm{g}$, which is in accordance with Chytiri et al. [2004] and Fidalgo et al. [2018]. After 10 days, loads reached about $4.95 \mathrm{CFU} / \mathrm{g}$ in control samples, showing a similar pattern to those reported by Chytiri et al. [2004]. Even though the Enterobacteriaceae count showed consistent contamination in the two groups, and treated samples at T10 showed a slight decrease in bacterial loads, there was no significant difference due to the treatment. In addition,
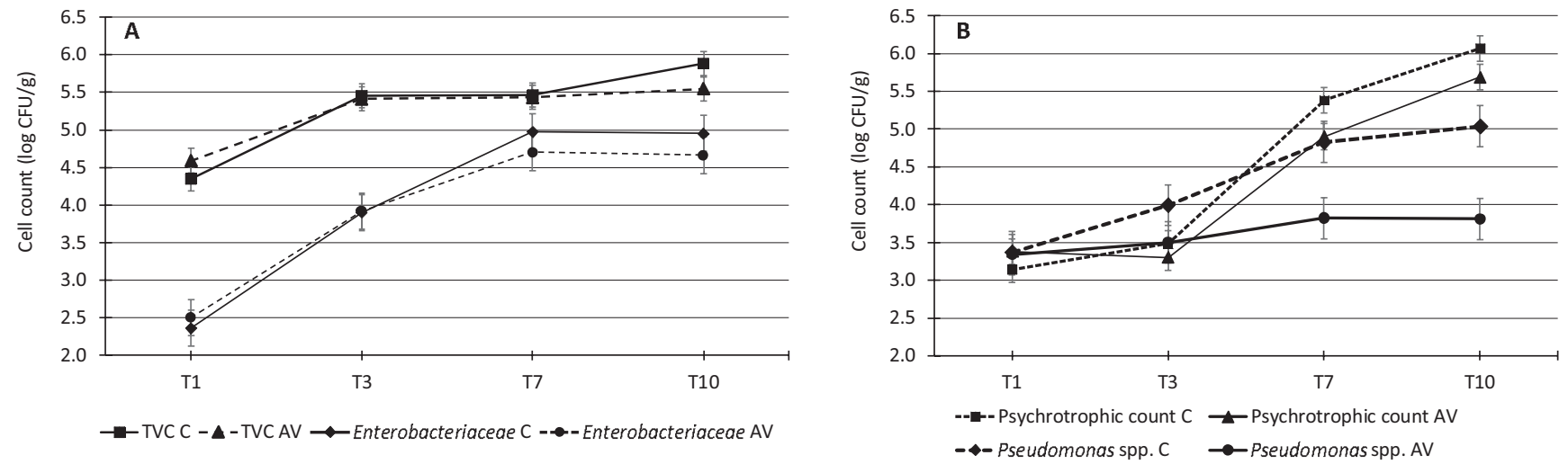

FIGURE 1. Total viable count (TVC), and Enterobacteriaceae (A), psychrotrophic and Pseudomonas spp. counts (B) of the salmon fillets throughout the storage time $(\mathrm{T} 1-2 \mathrm{~h}, \mathrm{~T} 3-3$ days, T7 - 7 days, T10 - 10 days). C - control group; AV - salmon fillets treated with aromatic vinegar. 
TABLE 1. Effects of the aromatic vinegar addition to salmon fillets on kinetic parameters describing the growth of bacterial loads performed (following Baranyi-Roberts models).

\begin{tabular}{lcccccc}
\hline $\begin{array}{l}\text { Kinetic parameters } \\
\text { of growth }\end{array}$ & Treatment & TVC & Enterobacteriaceae & Psychrophilic count & Pseudomonas spp. \\
\hline $\begin{array}{l}\text { Initial value } \\
\text { (log CFU/g) }\end{array}$ & $\mathrm{C}$ & 3.93 & 1.98 & 2.74 & 3.21 \\
\hline $\begin{array}{l}\text { Lag/shoulder } \\
(\mathrm{h})\end{array}$ & $\mathrm{AV}$ & 3.93 & 2.27 & 3.13 & 3.41 \\
\hline $\begin{array}{l}\mu \text { max } \\
(\log \text { CFU/g/h) }\end{array}$ & $\mathrm{C}$ & 17.15 & 16.95 & $39.07^{\mathrm{a}}$ & 25.37 \\
\hline $\begin{array}{l}\text { Final value } \\
\text { (log CFU/g) }\end{array}$ & $\mathrm{C}$ & 14.77 & 35.12 & $77.25^{\mathrm{b}}$ & 0.0372 & $0.0198^{\mathrm{b}}$ \\
\hline
\end{tabular}

Within each microbial load, different superscript letters $(a, b)$ indicate differences between treatments $(\mathrm{p} \leq 0.05)$. TVC - total viable count, $\mathrm{C}-$ control group, $\mathrm{AV}$ - salmon fillets with aromatic vinegar.

neither Salmonella spp. nor L. monocytogenes were detected in any of the samples tested.

The initial psychrotrophic load of control samples was $3.14 \log \mathrm{CFU} / \mathrm{g}$, similarly to that reported by Briones et al. [2010]. A limit of $10^{5} \mathrm{CFU} / \mathrm{g}$ for psychrotrophic bacteria has been suggested for fresh fish [Pons-Sànchez-Cascado et al., 2006], and this limit was exceeded after 7 and 10 days of storage for control and treated samples, respectively. A significant difference between treated and control samples was detected at T3 (7 days), considered the end of commercial shelf life for this kind of product. As shown in Table 1, the addition of the aromatic vinegar seems to influence the growth dynamics of psychrotrophic bacteria through extension of the lag phase $(\lambda)$ which also results in a lower final value. The initial Pseudomonas count showed values between 3.37 and $4.04 \log \mathrm{CFU} / \mathrm{g}$, i.e. slightly lower than those reported by Fidalgo et al. [2018] and in accordance with the loads reported by Chytiri et al. [2004] for filleted rainbow trout. However, in their study, a count of approximately $7 \log \mathrm{CFU} / \mathrm{g}$ was reached for fillets after 10-11 days of storage, which was considerably higher than the maximum of $4.04 \mathrm{log}$ $\mathrm{CFU} / \mathrm{g}$ found in this work. Furthermore, Pseudomonas counts reported the most relevant differences as there was a significant difference between groups at both $\mathrm{T} 3$ and $\mathrm{T} 10$. The $\mathrm{AV}$ affected both their $\mu$ max and final values.

Although the specific mechanisms of action have not been completely clarified, it has already been reported in the literature that, within a specific matrix, natural compounds (such as $\mathrm{R}(+)$ limonene, oregano, thyme, and star anise essential oils) may act differently on different bacteria [Giarratana et al., 2016; Huang et al., 2018], mainly due to the specific microbial response. The effect of vinegars on microbial population are depending on both organic acids and polyphenols [Bakir et al., 2017; Chen et al., 2016]. As regards organic acids, the main mechanism of action proposed involves the acidification of the bacterial cytoplasm after the compounds penetrated the cell membranes, and is not merely a question of the $\mathrm{pH}$ value of the solution adopted [Bakir et al., 2017; Kundukad et al., 2017]. The lower $\mathrm{pKa}$ of the organic acids than the $\mathrm{pH}$ of the cytoplasm causes their dissociation into hydrogen ions, the rise of the acidity inside the cell and damages to both struc- tural and functional proteins [Yagnik et al., 2018]. Furthermore, to counteract hydrogen ions concentration, a high quantity of energy is needed thus limiting the macromolecular synthesis and microbial growth [Van Immerseel et al., 2006]. Other proposed mechanisms of organic acids action are the increasing osmotic pressure and the production of antimicrobial peptides inside the cell [Chen et al., 2016]. Polyphenols either exert antimicrobial effects, depending on compounds structure and their concentration, through cell membrane disruption, interference with bacterial cell enzymes, and chelation of essential metals after they had penetrated the bacterial cell membrane [Chen et al., 2016; Daglia, 2012].

As mentioned before, for psychrotrophic bacteria, the $\mathrm{AV}$ inhibits the early steps of microbial growth and therefore influences the final concentration at the last sampling time, while for Pseudomonas spp., the effects are due to growth inhibition during the exponential phase.

Overall, the treatment had a positive effect, mainly on the inhibition of psychrotrophic bacteria and Pseudomonas spp. counts in salmon fillets, while no significant effect was observed on either TVC or Enterobacteriaceae count.

The microflora present in fish depends on the species, habitat, environment, harvesting method, and storage conditions and determines which bacteria are responsible for spoilage [Briones et al., 2010]. It is important to establish the count of Pseudomonas spp. as it represents the specific spoilage organism in freshwater fish [Gram \& Dalgaard, 2002]. Enterobacteriaceae count is a hygiene indicator [Mexis et al., 2009], and different enteric species of histamine-producing bacteria have also been isolated from fish. Moreover, Pseudomonas spp. have also been reported as histamine producers $[\mathrm{Hu}$ et al., 2014; Wang et al., 2017b].

The definition of a threshold value for spoilage microbial growth depends on the product and the microorganism considered. For sea products, especially fish, some studies report that level of specific spoilage flora, such as Pseudomonads and Enterobacteriaceae, accounting for $10^{7} \mathrm{CFU} / \mathrm{g}$ coincides with the appearance of irreversible alterations, therefore determining the end of the shelf-life [ICMSF, 1986; Koutsoumanis, 2001; Koutsoumanis \& Nychas 2000]. In the present 
study, the mentioned value was never reached in neither experimental group. Accordingly, the fillets remained at an acceptable standard for consumption throughout the storage.

\section{Biogenic amines (Bas) in salmon fillets}

BAs are non-volatile basic compounds formed by decarboxylation of the precursor amino acids as a result of metabolic processes of bacterial enzymes and are absent or present at very low levels in fresh fish [Chytiri et al., 2004; Pons-Sànchez-Cascado et al., 2006]. BAs are of importance due to food intoxication risk as they cause the most common food poisoning associated with fish consumption [Kim et al., 2009; Ozogul et al., 2017], and, although their formation in food does not necessarily correlate with the growth of spoilage organisms, they are useful chemical indicators of spoilage and thus of loss of freshness, hygienic quality of fish, and consumer acceptance [Kim et al., 2009; Pons-Sànchez-Cascado et al., 2006; Santos, 1996; Wunderlichová et al., 2014]. Although dominant microbial groups and concentrations in a fish species vary with temperature and storage conditions, affecting the formation of specific amines in the muscle [Chytiri et al., 2004], few studies have related bacterial and sensorial changes to BAs formation [Emborg et al., 2002]. Furthermore, Salmonidae have been regularly reported to cause histamine fish poisoning [Ozogul et al., 2017].

In this study, the presence of eight BAs was assessed but only seven were detected, namely 2-phenylethylamine, putrescine, cadaverine, histamine, tyramine, spermidine, and spermine; while tryptamine was not detected. Histamine content was the highest, reaching a final value of $59 \mathrm{mg} / \mathrm{kg}$ in the control samples after 10 days, whereas it was not detected in the treated samples. Thus, the aromatic vinegar exerted a positive effect on histamine production (Table 2). The European Community established a value for histamine at $200 \mathrm{mg} / \mathrm{kg}$ in fish [Regulation (EC) No 1019/2013] and the Food and Drug Administration (FDA) allows a lower level $(50 \mathrm{mg} / \mathrm{kg})$ [FDA, 2011]. This value was surpassed after 10 days of storage in the control samples.
In the control samples, contents of putrescine, cadaverine, and histamine increased steadily between days 7 (T2) and 10 (T3). Sensorial and microbiological data showed that $13 \mathrm{mg} / \mathrm{kg}$ of putrescine is the upper limit for spoilage initiation in fresh rainbow trout fillets [Chytiri et al., 2004]. This value was achieved at T10 in the control samples, but not in the AV group. The elevated content of histamine along with those of putrescine and cadaverine depicts bacterial spoilage of fish tissue. Indeed, the count of certain microbial groups is relevant, such as enterobacteria and pseudomonads that have been described as active BA-producing microorganisms in fish [Pons-Sànchez-Cascado et al., 2006]. As it has been reported by Chytiri et al. [2004], Pseudomonas spp. can lead to the synthesis of putrescine and cadaverine, as they are responsible for the carboxylation of lysine and ornithine, respectively. Moreover, putrescine and cadaverine can interfere with the histamine detoxification system, enhancing the toxicity of histamine [Kim et al., 2009].

Moreover, there was a significant difference between the control and treatment groups in tyramine levels throughout the storage time, with values established for the treatment groups being much lower than these determined for the control (Table 2).

\section{$\mathbf{p H}, \mathbf{a}_{\mathbf{w}}$, colour and TVB-N in salmon fillets}

The effect of the treatment and storage time on the $\mathrm{pH}$ value of salmon fillets is shown in Table 3. The initial $\mathrm{pH}$ value of the control and treated fillets was 6.13, which is in accordance with the mean cut-surface $\mathrm{pH}$ at time zero reported by Fletcher et al. [2002] and by Emborg et al. [2002]. During the study, $\mathrm{pH}$ remained stable, and only a slight decrease was reported after 3 days of storage, to 5.97 and 6.08 for $\mathrm{AV}$ and $\mathrm{C}$ groups, respectively. The $\mathrm{pH}$ values of salmon flesh decrease post mortem because of lactic acid formation, while increases are usually observed due to the production of basic nitrogen from bacterial growth [Briones et al., 2010]. Although there was an increase in the production of nitrogenous compounds during the storage period due to microbial growth, the $\mathrm{pH}$ did

TABLE 2. Biogenic amine content in salmon fillets, control and treated with aromatic vinegar $(\mathrm{mg} / \mathrm{kg})$, throughout the storage time.

\begin{tabular}{|c|c|c|c|c|c|c|c|c|}
\hline Treatment & Time & 2-PHE & PUT & CAD & HIS & TYR & SPD & SPM \\
\hline \multirow{4}{*}{$\mathrm{C}$} & $\mathrm{T} 1$ & $34.87 \pm 2.10$ & $8.62 \pm 5.45$ & - & - & $28.25 \pm 5.01^{\mathrm{b}}$ & $5.87 \pm 2.70$ & $25.75 \pm 3.49$ \\
\hline & $\mathrm{T} 3$ & $32.62 \pm 4.34$ & $6.25 \pm 4.46$ & - & - & $25.88 \pm 5.17^{b}$ & $6.00 \pm 2.39$ & $24.25 \pm 2.87$ \\
\hline & $\mathrm{T} 7$ & $32.12 \pm 5.43$ & $8.25 \pm 5.44$ & $10.12 \pm 4.19^{\text {bx }}$ & $8.25 \pm 3.79^{x}$ & $24.13 \pm 4.05^{\mathrm{b}}$ & $5.75 \pm 2.82$ & $23.38 \pm 2.96$ \\
\hline & $\mathrm{T} 10$ & $34.62 \pm 5.04$ & $12.87 \pm 8.63^{\mathrm{b}}$ & $45.13 \pm 14.94$ by & $58.63 \pm 13.56^{y}$ & $26.00 \pm 4.17^{b}$ & $5.62 \pm 2.13$ & $20.37 \pm 3.42$ \\
\hline \multirow{4}{*}{$\mathrm{AV}$} & $\mathrm{T} 1$ & $32.87 \pm 2.42$ & $5.37 \pm 3.85$ & - & - & $7.38 \pm 4.27^{\mathrm{a}}$ & $5.12 \pm 2.23$ & $22.12 \pm 2.70$ \\
\hline & $\mathrm{T} 3$ & $30.62 \pm 5.15$ & $4.37 \pm 4.00$ & $2.95 \pm 0.07^{\mathrm{a}}$ & - & $5.39 \pm 2.50^{\mathrm{a}}$ & $5.37 \pm 1.92$ & $23.58 \pm 2.77$ \\
\hline & $\mathrm{T} 7$ & $26.37 \pm 6.52$ & $5.25 \pm 4.27$ & $3.75 \pm 1.98^{\mathrm{a}}$ & - & $8.75 \pm 3.58^{\mathrm{a}}$ & $6.25 \pm 1.98$ & $20.39 \pm 3.29$ \\
\hline & $\mathrm{T} 10$ & $32.62 \pm 4.14$ & $5.37 \pm 3.81^{\mathrm{a}}$ & $4.25 \pm 1.67^{\mathrm{a}}$ & - & $9.25 \pm 3.33^{\mathrm{a}}$ & $5.38 \pm 2.26$ & $25.63 \pm 4.57$ \\
\hline
\end{tabular}

Data are expressed as mean \pm standard deviation.

$\mathrm{n}=8$ for each sampling point and each treatment; $\mathrm{C}$ - control group; AV - salmon fillets treated with aromatic vinegar; 2-PHE - 2-phenylethylamine; PUT - putrescine; CAD - cadaverine; HIS - histamine; TYR - tyramine; SPD - spermidine; SPM - spermine; T1 - 2 h; T3 - 3 days; T7 - 7 days; T10 - 10 days. Within each treatment, different superscript letters (x, y, z) indicate differences between storage periods ( $\leq 0.05$ ); within each storage period, different superscript letters $(a, b)$ indicate differences between treatments $(\mathrm{p} \leq 0.05)$. 
TABLE 3. Physical and chemical parameters ( $\mathrm{pH}$, colour and total volatile basic nitrogen values) of control and treated fillets throughout the storage experiment.

\begin{tabular}{|c|c|c|c|c|c|c|c|c|c|}
\hline \multirow{2}{*}{ Attribute } & \multirow{2}{*}{ Treatment } & \multicolumn{4}{|c|}{ Storage time } & \multirow{2}{*}{ SEM } & \multicolumn{3}{|c|}{$\mathrm{P}$ value } \\
\hline & & $\mathrm{T} 1$ & $\mathrm{~T} 3$ & $\mathrm{~T} 7$ & $\mathrm{~T} 10$ & & $\operatorname{Tr}$ & ST & $\operatorname{Tr} \times \mathrm{ST}$ \\
\hline \multirow{2}{*}{$\mathrm{pH}$} & $\mathrm{C}$ & 6.13 & 6.08 & 6.17 & 6.10 & \multirow{2}{*}{0.0125} & \multirow{2}{*}{0.384} & \multirow{2}{*}{0.132} & \multirow{2}{*}{0.536} \\
\hline & AV & 6.13 & 5.97 & 6.16 & 6.09 & & & & \\
\hline \multirow{2}{*}{$\mathrm{L}^{*}$} & $\mathrm{C}$ & 50.16 & 49.84 & 48.66 & 49.89 & \multirow{2}{*}{0.775} & \multirow{2}{*}{0.891} & \multirow{2}{*}{0.053} & \multirow{2}{*}{0.443} \\
\hline & $\mathrm{AV}$ & 51.03 & 50.63 & 47.71 & 48.88 & & & & \\
\hline \multirow{2}{*}{$a^{*}$} & $\mathrm{C}$ & $8.93^{w}$ & $10.66^{x}$ & $11.41^{x}$ & $11.82^{x}$ & \multirow{2}{*}{0.453} & \multirow{2}{*}{0.465} & \multirow{2}{*}{$<0.001$} & \multirow{2}{*}{0.156} \\
\hline & $\mathrm{AV}$ & 10.33 & 10.87 & 11.40 & 11.16 & & & & \\
\hline \multirow{2}{*}{$b^{*}$} & $\mathrm{C}$ & $14.02^{\mathrm{w}}$ & $16.10^{\mathrm{wx}}$ & $18.02^{\mathrm{x}}$ & $17.69^{x}$ & \multirow{2}{*}{0.706} & \multirow{2}{*}{0.414} & \multirow{2}{*}{$<0.001$} & \multirow{2}{*}{0.265} \\
\hline & $\mathrm{AV}$ & 15.71 & 17.18 & 17.57 & 17.01 & & & & \\
\hline \multirow{2}{*}{$\begin{array}{l}\text { TVB-N } \\
(\mathrm{mg} / 100 \mathrm{~g})\end{array}$} & $\mathrm{C}$ & $22.7^{\mathrm{w}}$ & $23.5^{\mathrm{w}}$ & $24.8^{x}$ & 29.3 & \multirow{2}{*}{0.027} & \multirow{2}{*}{0.139} & \multirow{2}{*}{$<0.001$} & \multirow{2}{*}{0.110} \\
\hline & $\mathrm{AV}$ & $21.9^{\mathrm{w}}$ & $23.8^{x}$ & $24.8^{y}$ & 28.7 & & & & \\
\hline
\end{tabular}

$\mathrm{n}=10$ samples for each treatment and sampling point; $\mathrm{C}$ - control group; AV - salmon fillets treated with aromatic vinegar; Tr - treatment; ST - Storage time; TVB-N - total volatile basic nitrogen; T1 - 2 h; T3 - 3 days; T7 - 7 days; T10 - 10 days. Within each storage period, different superscript letters $(\mathrm{a}, \mathrm{b})$ indicate differences between treatments $(\mathrm{p} \leq 0.05)$. Within each treatment, different superscript letters (w,X,y,z) indicate difference between storage times $(\mathrm{p} \leq 0.05)$.

not increase significantly during the experiment. Furthermore, the $\mathrm{pH}$ of the $\mathrm{AV}$ used was 6.2 and thus it was not able to alter the surface $\mathrm{pH}$ of the fish and induce protein denaturation.

The $\mathrm{a}_{\mathrm{w}}$ values did not vary either for the treatment or during storage, ranging from 0.985 to 0.986 at $\mathrm{T} 1$ and from 0.983 to 0.982 at $\mathrm{T} 3$ for $\mathrm{C}$ and $\mathrm{AV}$ groups, respectively. The values were high enough to promote microbial growth and spoilage of the fillets.

Indeed, when selecting salmon fillets, surface colour and appearance are important indicators for consumer acceptance and product final price, since pigmentation intensity is considered a quality characteristic for the salmonids [Fidalgo et al., 2018; Lerfall et al., 2016; Wang et al., 2017a].

The initial values of $\mathrm{L}^{*}$ (lightness), $\mathrm{a}^{*}$ (redness), and $\mathrm{b}^{*}$ (yellowness) were between 50.16 and 51.03, 8.93 and 10.33, and 14.02 and 15.71, respectively (Table 3). No significant differences were found in the $\mathrm{L}^{*}$ values between the two groups throughout storage, and both groups showed a slight but not significant decrease in lightness. This finding was unexpected as generally the $\mathrm{L}^{*}$ value increases during ice storage [Erikson \& Misimi, 2008] but limited changes are reported in salmon fillets stored in MAP conditions [Gimenez et al., 2005].

The $\mathrm{a}^{*}$ values increased during storage in the products but no difference was registered between the control and treated samples. These results are in accordance with those reported by Miraglia et al. [2016] in their study where $S$. salar raw fish was treated with a phenolic extract from olive vegetation water, and also by Fidalgo et al. [2018] for fresh Atlantic salmon during hyperbaric storage at room temperature. Moreover, the $\mathrm{a}^{*}$ values were lower than those reported by Wang et al. [2017a] and by Fidalgo et al. [2018]. The $b^{*}$ value followed the same trend as reported for the $a^{*}$ value. The increasing presence of both $a^{*}$ and $b^{*}$ color components, reported also by other authors [Erikson \& Misimi,
2008], could lead to a more brownish colour of the fillets, which could potentially affect their sensory quality. Despite no difference observed between the treated and untreated fillets, the AV seems to stabilize the $\mathrm{a}^{*}$ and $\mathrm{b}^{*}$ components, despite its pale-amber transparent colour not able to modify the original fillets colour.

However, the changes observed in salmon colour during storage may be caused mainly by microbial spoilage, enzymatic activity, oxidation processes, and different treatments applied to the samples, causing several structural changes to the muscle and variation of the colour parameters [Fidalgo et al., 2018].

TVB-N, which is constituted by trimethylamine (TMA-N), ammonia and other basic nitrogenous compounds, has been proposed as a quality indicator for spoilage in fresh and lightly preserved seafood [Dalgaard, 2000; Gram \& Dalgaard, 2002; Pons-Sànchez-Cascado et al., 2006; Sallam, 2007] since it shows a close relationship with sensory score [Pons-Sànchez-Cascado et al., 2006]. High values of TVB-N are not desirable since they indicate the existence of nitrogenous compounds deriving from the degradation, operated by proteolytic bacteria, of molecules containing nitrogenous compounds, such as proteins and nucleic acids [Wang et al., 2017a]. In the current study, the initial TVB-N values (mg N/100 g of product) ranged from 21.9 in the treated samples to 22.7 in the control samples (Table 3 ). Increases in the TVB-N values were detected throughout the storage period of the experiment, reaching values of 29.3 and $28.3 \mathrm{mg}$ $\mathrm{N} / 100 \mathrm{~g}$ by day 10 in the control and treated samples, respectively. The samples analysed during the experiment were all below the maximum value of $35 \mathrm{mg} \mathrm{N} / 100 \mathrm{~g}$ flesh stipulated by the EC guidelines for different species of raw fish [European Commission Decision 95/149/EC, 1995]. The initial content of TVB-N was higher than that reported by both 
Zaragozà et al. [2014] and Sallam [2007] who found initial TVB-N values in control samples of Pacific salmon below $10 \mathrm{mg} \mathrm{N} / 100 \mathrm{~g}$; and values of $22.7 \mathrm{mg} / 100 \mathrm{~g}$ muscle were reached only on day 9 . TVB-N increases are related to storage conditions, the activity of spoilage bacteria, and hygienic practices [Zaragozà et al., 2014], and TVB-N values are also affected by the species, season, harvesting area, age and sex of fish [Sallam, 2007]. The TVB-N content increased in all samples, which demonstrates their successive deterioration throughout the study.

\section{CONCLUSIONS}

The spoilage process in salmon fillets was monitored in this study via microbiological and physicochemical parameters in order to find some natural treatments that can influence microorganisms growth and their ability to produce BA, and therefore to obtain safe products. The hygienic level of the production was mostly high, as fillets showed a TVC always below $7 \log \mathrm{CFU} / \mathrm{g}$, even if a trend of increasing counts of Enterobacteriaceae and other spoiling bacteria was highlighted.

This preliminary study shows that the use of AV can really improve the overall hygienic quality of fresh salmon fillets stored in MAP, controlling the microbial populations in fish, such as Pseudomonas spp. and psychrotrophic loads. In particular, a significant effect was found on BAs production, with lower contents determined in the treated fillets for putrescine, cadaverine, tyramine, and histamine.

\section{REFERENCES}

1. Bakir, S., Devecioglu, D., Kayacan, S., Toydemir, G., Korbancioglu-Guler, F., Capanoglu, E. (2017). Investigating the antioxidant and antimicrobial activities of different vinegars. European Food Research and Technology, 243(12), 2083-2094.

2. Baranyi, J., Tamplin, M.L. (2004). ComBase: a common database on microbial responses to food environments. Journal of Food Protection, 67(9), 1967-1971.

3. Branciari, R., Ranucci, D., Urbani, E., Valiani, A., Trabalza-Marinucci, M., Dal Bosco, A., Franceschini, R. (2017). Freshwater fish burgers made from four different fish species as a valuable strategy appreciated by consumers for introducing EPA and DHA into a human diet. Journal of Aquatic Food Product Technology, 26(6), 686-694.

4. Briones, L.S., Reyes, J.E., Tabilo-Munizaga, G.E., Pérez-Won, M.O. (2010). Microbial shelf-life extension of chilled Coho salmon (Oncorhynchus kisutch) and abalone (Haliotis rufescens) by high hydrostatic pressure treatment. Food Control, 21(11), 1530-1535.

5. Chen, H., Chen, T., Giudici, P., Chen, F. (2016). Vinegar function on health: constituents, sources, and formation mechanisms. Comprehensive Reviews in Food Science and Food Safety, 15(6), 1124-1138.

6. Choulitoudi, E., Bravou, K., Bimpilas, A., Tsironi, T., Tsimogiannis, D., Taoukis, P., Oreopoulou, V. (2016). Antimicrobial and antioxidant activity of Satureja thymbra in gilthead seabream fillets edible coating. Food and Bioproducts Processing, 100, SI, 570-577.
7. Chytiri, S., Paleologos, E., Savvaidis, I., Kontominas, M.G. (2004). Relation of biogenic amines with microbial and sensory changes of whole and filleted freshwater rainbow trout (Onchorynchus mykiss) stored on ice. Journal of Food Protection, 67(5), 960-965.

8. CIE (1986). Commission International de 1'Eclairage. Publication No. 15.2: Colorimetry, 2nd ed., CIE Central Bureau, Wien, Austria.

9. Corbo, M.R., Bevilacqua, A., Campaniello, D., D’Amato, D., Speranza, B., Sinigaglia, M. (2009). Prolonging microbial shelf life of foods through the use of natural compounds and nonthermal approaches - a review. International Journal of Food Science and Technology, 44(2), 223-241.

10. Daglia, M. (2012). Polyphenols as antimicrobial agents. Current Opinion in Biotechnology, 23(2), 174-181.

11. Dalgaard, P. (2000). Fresh and lightly preserved seafood. In C. M. D. Man, \& A. A. Jones (Eds.), Shelf-Life Evaluation of Foods (2nd ed.). Gaithersburg, MD: Aspen Publishers, pp. 110-139.

12. Emborg, J., Laursen, B.G., Rathjen, T., Dalgaard, P. (2002). Microbial spoilage and formation of biogenic amines in fresh and thawed modified atmosphere-packed salmon (Salmo salar) at $2^{\circ}$ C. Journal of Applied Microbiology, 92(4), 790-799.

13. Erikson, U., Misimi, E. (2008). Atlantic salmon skin adn fillets color changes effected by perimortem handling stress, rigor mortis and ice storage. Journal of Food Science, 73(2), C50-C59.

14. European Commission (1995). 95/149/EC: Commission Decision of 8 March 1995 fixing the total volatile basic nitrogen (TVB-N) limit values for certain categories of fishery products and specifying the analysis methods to be used. Official Journal of the European Communities, L 097, 84-87.

15. FAO (2016). The state of world fisheries and aquaculture 2016. Contributing to food security and nutrition for all. Rome, Italy: Food and Agriculture Organization of the United Nations.

16. FDA (2011). Hazards and Controls Guidance Fourth Edition. Chapter 7: Scombrotoxin (Histamine) Formation in Fish and Fishery Products. Florida Sea Grant IFAS - Extension Bookstore University of Florida, Gainesville, FL, USA.

17. Fernández, K., Aspe, E., Roeckel, M. (2009). Shelf-life extension on fillets of Atlantic salmon (Salmo salar) using natural additives, superchilling and modified atmosphere packaging. Food Control, 20(11), 1036-1042.

18. Fidalgo, L.G., Lemos, A. T., Delgadillo, I., Saraiva, J.A. (2018). Microbial and physicochemical evolution during hyperbaric storage at room temperature of fresh Atlantic salmon (Salmo salar). Innovative Food Science and Emerging Technologies, 45, 264-272.

19. Fletcher, G.C., Summers, G., Corrigan, V., Cumarasamy, S., Dufour, J.P. (2002). Spoilage of king salmon (Oncorhynchus tshawytscha) fillets stored under different atmospheres. Journal of Food Science, 67(6), 2362-2374.

20. Giarratana, F., Muscolino, D., Beninati, C., Ziino, G., Giuffrida, A., Panebianco, A. (2016). Activity of R (+) limonene on the maximum growth rate of fish spoilage organisms and related effects on shelf-life prolongation of fresh gilthead sea bream fillets. International Journal of Food Microbiology, 237, 109-113.

21. Gimenez, B., Roncales, P., Beltran, J.A. (2005). The effects of natural antioxidant and lighting conditions on the quality of salmon (Salmo salar) fillets packaged in modified atmosphere. Journal of the Science of Food and Agriculture, 85 (6), 1033-1040.

22. Gram, L., Dalgaard, P. (2002). Fish spoilage bacteria - problems and solutions. Current Opinion in Biotechnology, 13(3), 262-266. 
23. Hu, Y., Huang, Z., Chen, X. (2014). Histamine-producing bacteria in blue scad (Decapterus maruadsi) and their abilities to produce histamine and other biogenic amines. World Journal of Microbiology and Biotechnology, 30(8), 2213-2221.

24. Huang, Z., Liu, X., Jia, S., Zhang, L., Luo, Y. (2018). The effect of essential oils on microbial composition and quality of grass carp (Ctenopharyngodon idellus) fillets during chilled storage. International Journal of Food Microbiology, 266, 52-59.

25. ICMSF (1986). Microorganisms in foods 2: sampling for microbiological analysis: principles and specific applications. Oxford: Blackwell Scientific Publications, pp. 127-278.

26. ISO standard 17410:2001. Microbiology of food and animal feeding stuffs. Horizontal method for the enumeration of psychrotrophic microorganisms. Geneva, Switzerland: International Organization for Standardization.

27. ISO standard 4833-1:2013. Microbiology of the food chain. Horizontal method for the enumeration of microorganisms. Part 1: colony count at 30 degrees $C$ by the pour plate technique. Geneva, Switzerland: International Organization for Standardization.

28. ISO standard 6579-1:2017. Microbiology of the food chain. Horizontal method for the detection, enumeration and serotyping of Salmonella. Part 1: detection of Salmonella spp. Geneva, Switzerland: International Organization for Standardization.

29. ISO standard 11290-1:2017. Microbiology of the food chain. horizontal method for the detection and enumeration of Listeria monocytogenes and of Listeria spp. Part 1: detection method. Geneva, Switzerland: International Organization for Standardization.

30. ISO standard 21528-2:2017. Microbiology of the food chain. Horizontal method for the detection and enumeration of Enterobacteriaceae. Part 2: colony-count technique. Geneva, Switzerland: International Organization for Standardization.

31. Kim, M.K., Mah, J.H., Hwang, H.J. (2009). Biogenic amine formation and bacterial contribution in fish, squid and shellfish. Food Chemistry, 116(1), 87-95.

32. Koutsoumanis, K. (2001). Predictive modeling of the shelf life of fish under nonisothermal conditions. Applied and Environmental Microbiology, 67(4), 1821-1829.

33. Koutsoumanis, K., Nychas, G.J.E. (2000). Application of a systematic experimental procedure to develop a microbial model for rapid fish shelf life predictions. International Journal of Food Microbiology, 60(2-3), SI, 171-184.

34. Kundukad, B., Schussman, M., Yang, K., Seviour, T., Yang, L., Rice, S.A., Kielleberg, S., Doyle, P.S. (2017). Mechanistic action of weak acid drugs on biofilms. Scientific Reports, 7, art. no. 4783.

35. Leisner, J.J., Gram, L. (2014). Spoilage of fish. In Butt and Tortorello (Eds.), Encyclopedia of Food Microbiology $2^{\text {nd }}$ Ed. Academic Press, London, UK, pp. 813-820.

36. Lerfall, J., Bendiksen, E.Å., Olsen, J.V., Morrice, D., Østerlie, M. (2016). A comparative study of organic- versus conventional farmed Atlantic salmon. I. Pigment and lipid content and composition, and carotenoid stability in ice-stored fillets. Aquaculture, 451, 170-177.

37. Lingham, T., Besong, S., Ozbay, G., Lee, J.L. (2012). Antimicrobial activity of vinegar on bacterial species isolated from retail and local channel catfish (Ictalurus punctatus). Food Processing and Technology, S11-001 [http://dx.doi.org/10.4172/2157-7110. S11-001].

38. Machado, M.M., dos Santos Montagner, G.F.F., Boligon, A., Athayde, M.L., da Rocha, M.I.U.M., Lera, J.P.B., Belló, C., da
Cruz, I.B.M. (2011). Determination of polyphenol contents and antioxidant capacity of no-alcoholic red grape products ( $\mathrm{Vi}$ tis labrusca) from conventional and organic crops. Quimica Nova, 34(5), 798-803.

39. Medina, E., Romero, C., Brenes, M., de Castro, A. (2007). Antimicrobial activity of olive oil, vinegar, and various beverages against foodborne pathogens. Journal of Food Protection, 70(5), 1194-1199.

40. Mexis, S.F., Chouliara, E., Kontominas, M.G. (2009). Combined effect of an oxygen absorber and oregano essential oil on shelf life extension of rainbow trout fillets stored at $4^{\circ} \mathrm{C}$. Food Microbiology, 26(6), 598-605.

41. Miks-Krajnik, M., Yoon, Y.J., Ukuku, D.O., Yuk, H.G. (2016). Volatile chemical spoilage indexes of raw Atlantic salmon (Salmo salar) stored under aerobic condition in relation to microbiological and sensory shelf lives. Food Microbiology, 53, 182-191.

42. Miraglia, D., Esposto, S., Branciari, R., Urbani, S., Servili, M., Perucci, S., Ranucci, D. (2016). Effect of a phenolic extract from olive vegetation water on fresh salmon steak quality during storage. Italian Journal of Food Safety, 5, 224-228.

43. Miraglia, D., Ranucci, D., Trabalza-Marinucci, M., Acuti, G., Forte, C., Codini, M., Roila, R., Branciari, R. (2017). Microbiological, chemical-physical and sensory characteristics of Fabriano salami from pigs fed Oregano vulgaris extract. Italian Journal of Food Safety, 6, 203-207.

44. Ozogul, F., Oztekin, R., Kulawik, P. (2017). Biogenic amine formation and microbiological quality of anchovy (Engraulis encrasicolus) treated with lavender and lemon balm ethanol extracts. Journal of Food Science, 82(5),1278-1284.

45. Pearson, D. (1991). Chapter 13. Flesh foods. In D. Pearson (Ed.), The Chemical Analysis of Food. Churchill, New York, London, pp. 510-512.

46. Pons-Sànchez-Cascado, S., Veciana-Nogués, M.T., Bover-Cid, S., Mariné-Font, A., Vidal-Carou, M.C. (2006). Use of volatile and non-volatile amines to evaluate the freshness of anchovies stored in ice. Journal of the Science of Food and Agriculture, 86(5), 699-705.

47. Rashidinejad, A., Birch, E.J., Sun-Waterhouse, D., Everett, D.W. (2013). Effects of catechin on the phenolic content and antioxidant properties of low-fat cheese. International Journal of Food Science and Technology, 48(12), 2448-2455.

48. Regulation (EC) No 1019/2013 of 23 October 2013 amending Annex I to Regulation (EC) No 2073/2005 as regards histamine in fishery products. Official Journal of the European Union, L282, 24 October 2013, 46-47.

49. Sallam, K.I. (2007). Chemical, sensory and shelf life evaluation of sliced salmon treated with salts of organic acids. Food Chemistry, 101 (2), 592-600.

50. Santos, M.H.S. (1996). Biogenic amines: their importance in foods. International Journal of Food Microbiology, 29(2-3), 213-231.

51. Sivertsvik, M., Rosnes, J.T., Kleiberg, G.H. (2003). Effect of modified atmosphere packaging and superchilled storage on the microbial and sensory quality of Atlantic salmon (Salmo salar) fillets. Journal of Food Science, 68(4), 1467-1472.

52. Tacon, A.G.J., Metian, M. (2013). Fish matters: importance of aquatic foods in human nutrition and global food supply. Reviews in Fisheries Science, 21 (1), 22-38.

53. Van Immerseel, F., Russell, J.B., Flythe, M.D., Gantois, I., Timbermont, L., Pasmans, F., Haesebrouck, F., Ducatelle, R. (2006). 
The use of organic acids to combat Salmonella in poultry: a mechanistic explanation of the efficacy. Avian Pathology, 35(3), 182-188.

54. Wang, Z., Hu, S., Gao, Y., Ye, C., Wang, H. (2017a). Effect of collagen-lysozyme coating on fresh-salmon fillets preservation. LWT - Food Science and Technology, 75, 59-64.

55. Wang, H., Liu, X., Zhang, Y., Lu, H., Xu, Q., Shi, C., Luo, Y. (2017b). Spoilage potential of three different bacteria isolated from spoiled grass carp (Ctenopharyngodon idellus) fillets during storage at $4^{\circ} \mathrm{C}$. LWT - Food Science and Technology, 81, $10-17$.

56. Wunderlichová, L., Buňková, L., Koutný, M., Jančová, P., Buňka, F. (2014). Formation, degradation, and detoxification of putrescine by foodborne bacteria: a review. Comprehensive Reviews in Food Science and Food Safety, 13(5), 1012-1030.
57. Yagnik, D., Serafin, V., Shah, A. J. (2018). Antimicrobial activity of apple cider vinegar against Escherichia coli, Staphylococcus aureus and Candida albicans; downregulating cytokine and microbial protein expression. Scientific Reports, 8, art. no. 1732.

58. Zaragozá, P., Fernández-Segovia, I., Fuentes, A., Vivancosa, J.L., Ros-Lisa, J.V., Barat, J.M., Martínez-Mánez, R. (2014). Monitorization of Atlantic salmon (Salmo salar) spoilage using an optoelectronic nose. Sensors and Actuators B: Chemical, 195, 478-485.

59. Zhai, H., Yang, X., Li, L., Xia, G., Cen, J., Huang, H., Hao, S. (2012). Biogenic amines in commercial fish and fish products sold in southern China. Food Control, 25(1), 303-308.

Submitted: 27 June 2019. Revised: 29 August and 18 September 2019. Accepted: 27 September 2019. Published on-line: 28 October 2019. 